Profil Tingkat Kesegaran Jasmani....(M.Taheri Akbar \& Fery Hidayad)

\title{
PROFIL TINGKAT KESEGARAN JASMANI MAHASISWA PENDIDIKAN OLAHRAGA FKIP UNIVERSITAS PGRI PALEMBANG
}

\author{
Oleh: M. Taheri Akhbar ${ }^{1}$ Fery Hidayad $^{2}$ \\ (Dosen Universitas PGRI Palembang) \\ Email : mtaheriakhbar@univpgri-palembang.ac.id
}

\begin{abstract}
Abstrak
Masalah penelitian adalah belum diketahuinya tingkat kesegaran jasmani mahasiswa Pendidikan Olahraga FKIP Universitas PGRI Palembang Tahun Akademik 2018-2019. Penelitian ini bertujuan untuk mengetahui Tingkat Kesegaran Jasmani Mahasiswa Pendidikan Olahraga FKIP Universitas PGRI Palembang Tahun Akademik 2018-2019. Subyek dari penelitian ini adalah mahasiswa semester I Pendidikan Olahraga berjumlah 73 orang. Metode Penelitian ini menggunakan metode deskriptif kuantitatif. Teknik pengumpulan data menggunakan tes, Instrumen yang digunakan dalam penelitian ini berupa tes TKJI. Teknik analisis data menggunakan rumus presentase. Hasil penelitian menunjukan dari 73 mahasiswa pendidikan olahraga semester I setelah dianalisis menggunakan rumus presentase terdapat 3 mahasiswa masuk kategori baik sekali sebesar 4,11\%, 9 mahasiswa masuk kategori Baik sebesar 12,33\%, 50 mahasiswa masuk kategori Sedang sebesar 68,49\%, 11 orang mahasiswa masuk kategori kurang sebesar 15,07\%, dan kategori kurang sekali 0\%. Kesimpulan adalah tingkat kesegaran jasmani mahasiswa Program Studi Pendidikan Olahraga semester I Universitas PGRI Palembang rata-rata masuk kedalam kategori Sedang sebesar $68,49 \%$.
\end{abstract}

Kata kunci: Tingkat Kesegaran Jasmani, Mahasiswa Pendidikan Olahraga

\section{PROFILE OF PHYSICAL FITNESS LEVEL OF FKIP UNIVERSITY SPORTS EDUCATION STUDENTS AT PGRI PALEMBANG}

\begin{abstract}
The research problem is the lack of knowledge about the phsycal fitness level of FKIP Sports Education Students in the academic year 2018-2019. This study aims to find out the phsycal fitness level of FKIP Sports Education Students in the academic year OF Palembang 2018-2019. The subjects of this study were 73 first semester students in sport education. This research method uses quantitative descriptive method. Data collection techniques use tests, the instruments used in this study are TKJI tests. Data analysis techniques use a percentage formula. The results of the study showed that from 73 semester 1 sports education students after being analyzed using the percentage formula there werw 3 students in the excellent category of 4,11\%, 9 students in the good category at 12,33\%, 50 students in the moderate category at 68,49\%, 11 students in the less category of 15,07\% and the category is less than 0\%. The conclusion is that the level of phsical fitness of students in the first semester sports education
\end{abstract}


study program at FKIP University of PGRI Palembang is in the medium category of $68,49 \%$.

Keywords: Level of Physical Fitness, Sports Education Students

\section{A. PENDAHULUAN}

Peningkatan kualitas sumber daya manusia merupakan syarat mutlak untuk mencapai tujuan pembangunan. Tujuan pendidikan adalah seperangkat hasil pendidikan yang dicapai oleh peserta didik setelah diselenggarakannya kegiatan pendidikan. Seluruh kegiatan pendidikan yakni bimbingan dan latihan diarahkan untuk mencapai tujuan pendidikan. Dalam konteks ini, tujuan pendidikan merupakan komponen sistem pendidikan yang menempati kedudukan dan fungsi sentral (Hamalik, 2003:3).

Salah satu faktor penentu dalam tercapainya keinginan untuk mengangkat prestasi olahraga adalah kesegaran jasmani. Dengan tingkat kesegaran jasmani yang baik maka seorang mahasiswa akan memiliki kesanggupan untuk menjalankan tugas atau beban kerja yang diberikan kepadanya, kesegaran yang baik sangat membantu dalam produktivitas dirinya sebagai pelajar sehingga akan belajar dengan giat dan rajin, tangkas menyelesaikan berbagai tugas dan tidak mudah menyerah, sebaliknya bagi yang tingkat kesegaran jasmaninya rendah cenderung akan mudah sakit. Hal ini akan berakibat kepada yang bersangkutan tidak akan sanggup menjalankan beban tugas yang diberikan.

Berdasarkan pengamatan di Program Studi Pendidikan Olahraga, tingkat kesegaran jasmani mahasiswa sangat beragam. Masih banyak mahasiswa yang kurang energik dalam kegiatan perkuliahan. Hal inilah yang menjadi landasan peneliti untuk melihat kesegaran jasmani mahasiswa prodi olahraga FKIP Universitas PGRI Palembang.

Derajat kesegaran jasmani dapat ditingkatkan melalui keterampilan gerak dasar dan kesehatan melalui pengenalan penggunaan sikap positif dan pengamatan sikap mental yang diimplementasikan dalam berbagai aktivitas agar dapat mencapai pertumbuhan jasmani khususnya tinggi badan dan berat yang 
ideal, secara harmonis dan perkembangan jasmani.

Mutohir (2007:117) menyatakan kesegaran jasmani adalah "kemampuan seseorang yang melakukan tugas-tugas sehari-hari tanpa harus mengalami kelelahan yang berarti”. Menurut Hairy (2007:1.16) kesegaran jasmani tergantung kepada dua komponen dasar, yaitu kebugaran organik (organic fitness) dan kebugaran organik (dynamic fitness). Dua komponen itu sangat penting didalam kebugaran jasmani secara keseluruhan dan interaksi keduanya itu yang menentukan tingkat kebugaran jasmani yang dimiliki.

Kesegaran jasmani, dimaksudnya sifat-sifat khusus yang dimiliki berdasarkan garis keturunan, yang diwarisi oleh kedua orang tua atau bahkan generasi sebelumnya dan dipengaruhi oleh umur dan mungkin oleh keadaan sakit atau kecelakaan termasuk akibat perang. Jika berbicara tentang ukuran tubuh, perkembangannya serta ciri-ciri fisik lainnya, misalnya seseorang berasal dari keturunan sebaliknya. Keadaan yang berhubungan dengan organisme sebenarnya bersifat statis dan sulit atau bahkan tidak mungkin untuk diubah. Tingkat kebugaran organik menentukan potensi kebugaran jasmani secara keseluruhan.

Menurut Luthan (2002:1) kesegaran jasmani mempunyai dua aspek atau komponen yaitu Kekuatan otot, Daya tahan otot, Daya tahan aerobic, Fleksibilitas. Kesegaran yang berkaitan dengan performa: Koordinasi, Agilitas, Kecepatan gerak, Power, Keseimbangan.

\section{B. METODOLOGI PENELITIAN}

Dalam penelitian ini, peneliti menggunakan teknik purposive sampling. Teknik purposive sampling adalah teknik pengambilan sampel sumber data dengan pertimbangan tertentu (Sugiyono, 2011:124). Berdasarkan pendapat ahli tersebut maka yang menjadi sampel dalam penelitian ini adalah sebagian mahasiswa laki-laki prodi pendidikan olahraga yang berjumlah 73 orang.

Teknik atau cara-cara yang dapat digunakan oleh peneliti untuk mengumpulkan data. Teknik menunjuk suatu kata yang abstrak dan tidak diwujudkan dalam benda, tetapi hanya dapat dilihat penggunaannya memalui: 
angket, wawancara pengamatan, ujian (tes), dokumentasi dan lainnya. Peneliti dapat menggunakan salah satu atau gabungan tergantung dari masalah yang dihadapi (Riduwan, 2009:69). Adapun teknik pengumpulan data dalam penelitian ini adalah dengan teknik observasi dan tes, adapun tes yang digunakan adalah tes kesegaran jasmani indonesia (TKJI) antara lain Lari 50 meter, Angkat tubuh selama 30 detik, Baring duduk selama 30 detik, Loncat tegak, Lari/jalan jarak 600 meter (Kementerian Pendidikan Nasional, 2010).

Nasution dalam Sugiyono (2011:334), menyatakan bahwa "Melakukan analisis adalah pekerjaan yang sulit, memerlukan kerja keras. Analisis memerlukan daya kreatif serta kemampuan intelektual yang tinggi. Tidak ada cara tertentu yang dapat diikuti untuk mengadakan analisis, sehingga setiap penelitian harus mencari sendiri metode yang dirasakan cocok dengan sifat penelitiannya”. Analisis data yang digunakan yaitu dengan rumus Presentase.

$\mathrm{P}=\frac{F}{N} \times 100 \%$

Keterangan:

$\mathrm{P}=$ Persentase yang dicari

$\mathrm{F}=$ Frekuensi (Jumlah Pilihan Angket)

$\mathrm{N}=$ Jumlah Sampel atau Responden

\section{HASIL PENELITIAN DAN PEMBAHASAN}

\section{Deskripsi Data Hasil Penelitian}

\section{a) Hasil Lari 50 Meter}

Berdasarkan hasil pengukuran lari 50 meter, diperoleh skor maksimum 10,21 detik tergolong kategori kurang dan skor minimum 6,10 detik tergolong kategori baik sekali. Selanjutnya, hasil analisis data lari 50 meter mahasiswa Prodi Olahraga FKIP Universitas PGRI Palembang dapat diperoleh data distribusi frekuensi sebagai berikut:

Tabel. 1 Distribusi Frekuensi Lari 50 Meter

\begin{tabular}{|c|c|c|c|c|}
\hline \multirow{2}{*}{ No } & \multirow{2}{*}{$\begin{array}{c}\text { Kelas Interval } \\
\text { (detik) }\end{array}$} & \multicolumn{2}{|c|}{ Frekuensi } & \multirow{2}{*}{ Kategori } \\
\cline { 3 - 4 } & S.d-6,7" & 6 & 8.2 & Baik Sekali \\
\hline 1 & S.d & &
\end{tabular}




\begin{tabular}{|c|c|c|c|c|}
\hline \multirow{2}{*}{ No } & \multirow{2}{*}{$\begin{array}{c}\text { Kelas Interval } \\
\text { (detik) }\end{array}$} & \multicolumn{2}{|c|}{ Frekuensi } & \multirow{2}{*}{ Kategori } \\
\hline & & Absolut (Fa) & Relatif (\%) & \\
\hline 2 & $6,8^{\prime \prime}-7,6^{\prime \prime}$ & 9 & 12.3 & Baik \\
\hline 3 & $7,7^{\prime \prime}-8,7^{\prime \prime}$ & 47 & 64.4 & Sedang \\
\hline 4 & $8,8^{\prime \prime}-10,3^{\prime \prime}$ & 11 & 15.1 & Kurang \\
\hline 5 & $10,4^{\prime \prime}-\mathrm{dst}$ & 0 & 0 & Kurang Sekali \\
\hline & Jumlah & 73 & 100 & - \\
\hline
\end{tabular}

Agar lebih jelasnya data hasil lari $50 \mathrm{~m}$ dapat dilihat pada gambar histogram 1 berikut:

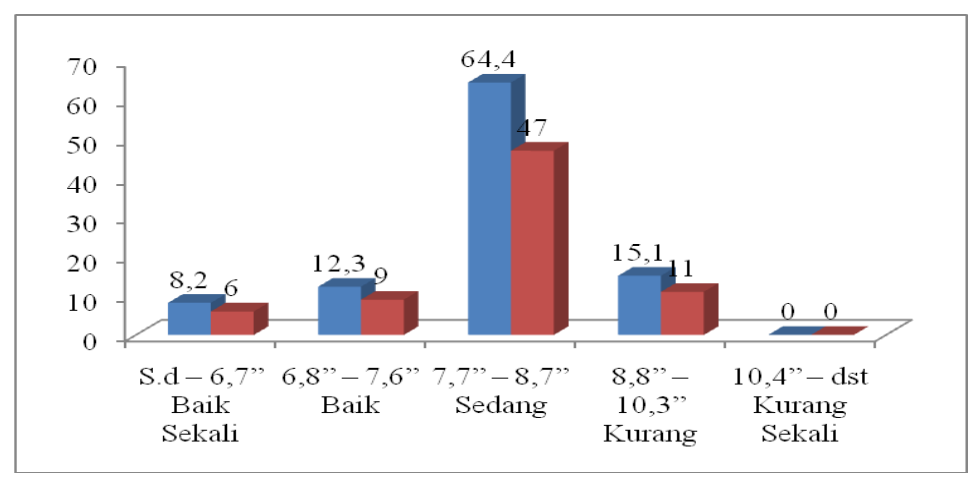

Histogram 1: Lari 50 m mahasiswa

Berdasarkan histogram data hasil lari 50 meter di atas dari 73 orang siswa, 6 orang $(8,2 \%)$ tergolong kategori baik sekali, 9 orang $(12,3 \%)$ tergolong kategori baik, 47 orang 64,4\%) tergolong kategori sedang dan 11 orang (15,1\%). Sedangkan yang tergolong kategori kurang sekali tidak ada (0\%). Berdasarkan hasil kajian di atas dapat dikemukakan bahwa rata-rata skor lari $50 \mathrm{~m}$ adalah 7,9 detik berada dalam kategori sedang.

\section{b) Hasil Gantung Angkat Tubuh}

Berdasarkan hasil tes gantung angkat tubuh, diperoleh skor maksimum 15 kali tergolong kategori baik dan skor minimum 4 kali tergolong kategori kurang. Selanjutnya, hasil pengukuran tes gantung angkat tubuh dapat diperoleh data distribusi sebagai berikut:

Tabel. 2 Distribusi Frekuensi Gantung Angkat Tubuh

\begin{tabular}{|c|c|c|c|c|}
\hline \multirow{2}{*}{ No } & \multirow{2}{*}{$\begin{array}{c}\text { Kelas Interval } \\
\text { (kali) }\end{array}$} & \multicolumn{2}{|c|}{ Frekuensi } & \multirow{2}{*}{ Kategori } \\
\hline & & Absolut (Fa) & Relatif (\%) & \\
\hline 1 & 16 ke atas & 0 & 0 & Baik Sekali \\
\hline 2 & $11-15$ & 16 & 21.9 & Baik \\
\hline
\end{tabular}




\begin{tabular}{|c|c|c|c|c|}
\hline \multirow{2}{*}{ No } & \multirow{2}{*}{$\begin{array}{c}\text { Kelas Interval } \\
\text { (kali) }\end{array}$} & \multicolumn{2}{|c|}{ Frekuensi } & \multirow{2}{*}{ Kategori } \\
\cline { 3 - 4 } & $6-10$ & 52 & 71.2 & Sedang \\
\hline 3 & $2-5$ & 5 & 6.8 & Kurang \\
\hline 4 & $0-1$ & 0 & 0 & Kurang Sekali \\
\hline 5 & Jumlah & 73 & 100 & - \\
\hline \multicolumn{2}{|r|}{} \\
\hline
\end{tabular}

Agar lebih jelasnya hasil gantung angkat tubuh dapat dilihat pada gambar histogram berikut:

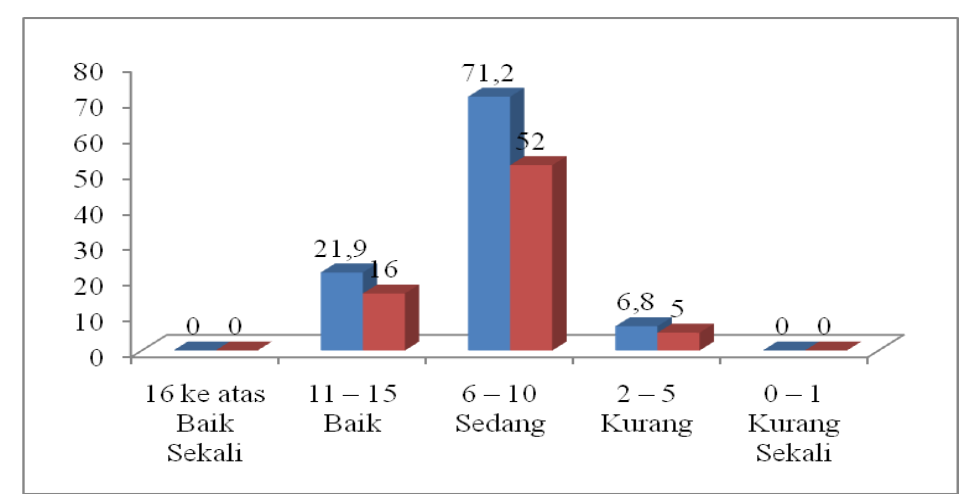

\section{Histogram 2 Gantung Angkat Tubuh Mahasiswa}

Dari histogram data hasil gantung angkat tubuh di atas dari 73 orang siswa, 16 orang $(21,9 \%)$ tergolong kategori baik, 52 orang $(71,2 \%)$ tergolong kategori sedang dan 5 orang $(6,8 \%)$ tergolong kategori kurang. Sedangkan untuk kategori baik sekali dan kurang sekali tidak ada (0\%). Berdasarkan hasil kajian di atas dapat dikemukakan bahwa rata-rata kemampuan gantung angkat tubuh mahasiswa adalah 9 kali tergolong kategori sedang.

\section{c) Baring Duduk 30 detik}

Berdasarkan hasil tes baring duduk 30 detik diperoleh skor maksimum 37 kali tergolong kategori baik dan skor minimum 17 kali tergolong kategori kurang. Selanjutnya, tabel hasil tes baring duduk 30 detik mahasiswa dapat diperoleh data distribusi sebagai berikut:

Tabel. 3 Distribusi Frekuensi Baring Duduk 30 Detik

\begin{tabular}{|c|c|c|c|c|}
\hline \multirow{2}{*}{ No } & \multirow{2}{*}{$\begin{array}{l}\text { Kelas Interval } \\
\text { (kali) }\end{array}$} & \multicolumn{2}{|c|}{ Frekuensi } & \multirow{2}{*}{ Kategori } \\
\hline & & Absolut (Fa) & Relatif (\%) & \\
\hline 1 & $38 \mathrm{ke}$ atas & 0 & 0 & Baik Sekali \\
\hline 2 & $28-37$ & 17 & 23.3 & Baik \\
\hline
\end{tabular}




\begin{tabular}{|c|c|c|c|c|}
\hline \multirow{2}{*}{ No } & \multirow{2}{*}{$\begin{array}{c}\text { Kelas Interval } \\
\text { (kali) }\end{array}$} & \multicolumn{2}{|c|}{ Frekuensi } & \multirow{2}{*}{ Kategori } \\
\hline & & Absolut (Fa) & Relatif (\%) & \\
\hline 3 & $19-27$ & 54 & 74 & Sedang \\
\hline 4 & $8-18$ & 2 & 2.7 & Kurang \\
\hline 5 & $0-7$ & 0 & 0 & Kurang Sekali \\
\hline \multicolumn{2}{|r|}{ Jumlah } & 73 & 100 & - \\
\hline
\end{tabular}

Agar lebih jelasnya hasil baring duduk 30 detik dapat dilihat pada gambar histogram 3 sebagai berikut:

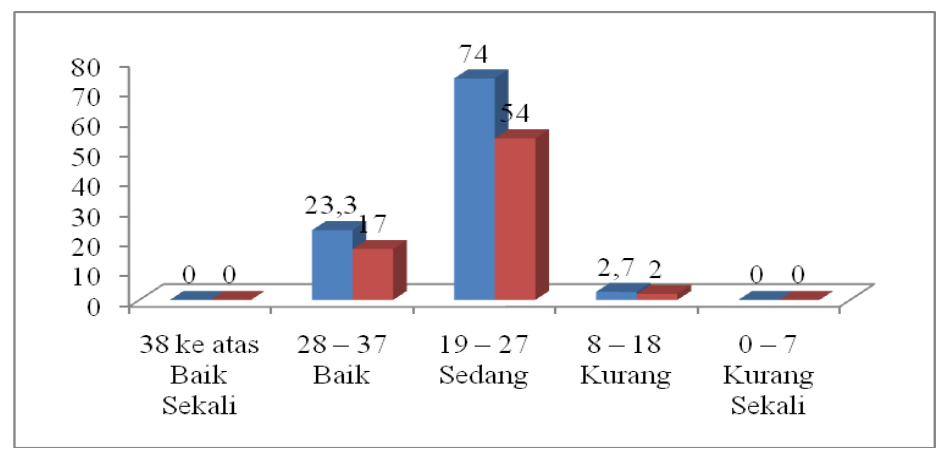

Histogram 3 : Tingkat Baring Duduk 30 Detik

Dari histogram data hasil tingkat baring duduk 30 detik di atas dari 73 orang siswa, 17 orang $(23,3 \%)$ tergolong kategori baik, 54 orang $(74 \%)$ tergolong kategori sedang dan 2 orang $(2,7 \%)$ tergolong kategori kurang. Sedangkan untuk kategori baik sekali dan kurang sekali (0\%). Berdasarkan hasil kajian di atas, dapat dikemukakan bahwa baring duduk 30 detik adalah 24 kali tergolong kategori sedang.

\section{d) Loncat tegak}

Berdasarkan hasil tes loncat tegak, diperoleh skor maksimum $67 \mathrm{~cm}$ tergolong kategori baik sekali dan skor minimum $31 \mathrm{~cm}$ tergolong kategori kurang. Berdasarkan tabel hasil pengukuran loncat tegak diperoleh data distribusi sebagai berikut:

Tabel. 4 Distribusi Frekuensi Loncat Tegak

\begin{tabular}{|c|c|c|c|c|}
\hline \multirow{2}{*}{ No } & \multirow{2}{*}{$\begin{array}{l}\text { Kelas Interval } \\
\text { (cm) }\end{array}$} & \multicolumn{2}{|c|}{ Frekuensi } & \multirow{2}{*}{ Kategori } \\
\hline & & Absolut (Fa) & Relatif (\%) & \\
\hline 1 & 66 ke atas & 2 & 2.7 & Baik Sekali \\
\hline 2 & $53-65$ & 14 & 19.2 & Baik \\
\hline 3 & $42-52$ & 44 & 60.3 & Sedang \\
\hline 4 & $31-41$ & 13 & 17.8 & Kurang \\
\hline
\end{tabular}




\begin{tabular}{|c|c|c|c|c|}
\hline \multirow{2}{*}{ No } & \multirow{2}{*}{$\begin{array}{c}\text { Kelas Interval } \\
(\mathbf{c m})\end{array}$} & \multicolumn{2}{|c|}{ Frekuensi } & \multirow{2}{*}{ Kategori } \\
\cline { 3 - 4 } & s.d 30 & 0 & 0 & Kurang Sekali \\
\hline 5 & Jumlah & 73 & 100 & - \\
\hline
\end{tabular}

Agar lebih jelasnya hasil loncat tegak dapat dilihat pada gambar histogram sebagai berikut:

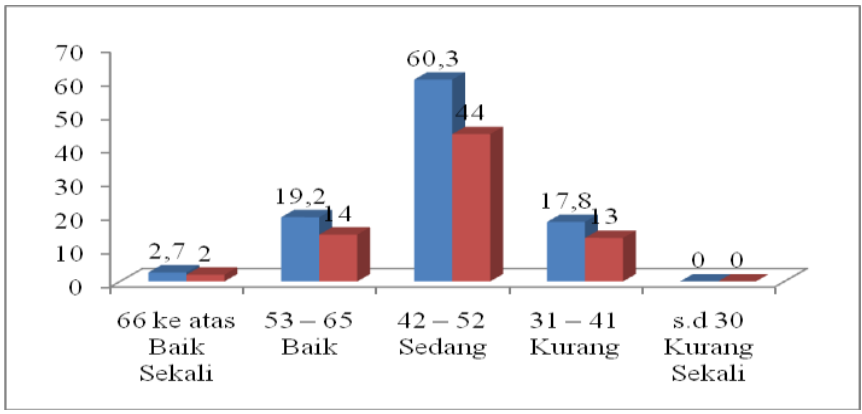

Histogram 4 : Loncat Tegak

Dari histogram data hasil loncat tegak di atas dari 73 orang siswa, 2 orang $(2,7 \%)$ tergolong kategori baik sekali, 14 orang $(19,2 \%)$ tergolong kategori baik, 44 orang $(60,3 \%)$ tergolong kategori sedang dan 13 orang $(17,8 \%)$ tergolong kategori kurang. Sedangkan yang tergolong kategori kurang sekali tidak ada (0\%). Berdasarkan hasil tes di atas dapat dikemukakan bahwa kemampuan loncat tegak adalah 46,61 cm tergolong kategori sedang.

\section{e) Lari 600 meter}

Berdasarkan hasil tes lari 600 meter diperoleh skor maksimum 6'02" detik tergolong kategori kurang dan skor minimum 3" detik tergolong kategori baik sekali. Selanjutnya, tabel hasil tes lari 600 meter dapat diperoleh data distribusi sebagai berikut:

Tabel. 5 Distribusi Frekuensi Lari 600 Meter

\begin{tabular}{|c|c|c|c|c|}
\hline \multirow{2}{*}{ No } & \multirow{2}{*}{$\begin{array}{c}\text { Kelas Interval } \\
\text { (detik) }\end{array}$} & \multicolumn{2}{|c|}{ Frekuensi } & \multirow{2}{*}{ Kategori } \\
\cline { 3 - 4 } & S.d - 3'04" & 3 & 4.1 & Baik Sekali \\
\hline 1 & Absolut (Fa) $^{\prime \prime}$ & Relatif (\%) & Baik \\
\hline 2 & $3^{\prime} 05^{\prime \prime}-3^{\prime} 53^{\prime \prime}$ & 10 & 13.7 & Sedang \\
\hline 3 & $3^{\prime} 54^{\prime \prime}-4^{\prime} 46^{\prime \prime}$ & 47 & 64.4 & Kurang \\
\hline 4 & $4^{\prime} 47^{\prime \prime}-6^{\prime} 04^{\prime \prime}$ & 13 & 17.8 & Kurang Sekali \\
\hline 5 & $6^{\prime} 05^{\prime \prime}-$ dst & 0 & 0 & \\
\hline
\end{tabular}




\begin{tabular}{|c|c|c|c|}
\hline Jumlah & 73 & 100 & - \\
\hline
\end{tabular}

Agar lebih jelasnya hasil lari 600 meter dapat dilihat pada gambar histogram sebagai berikut:

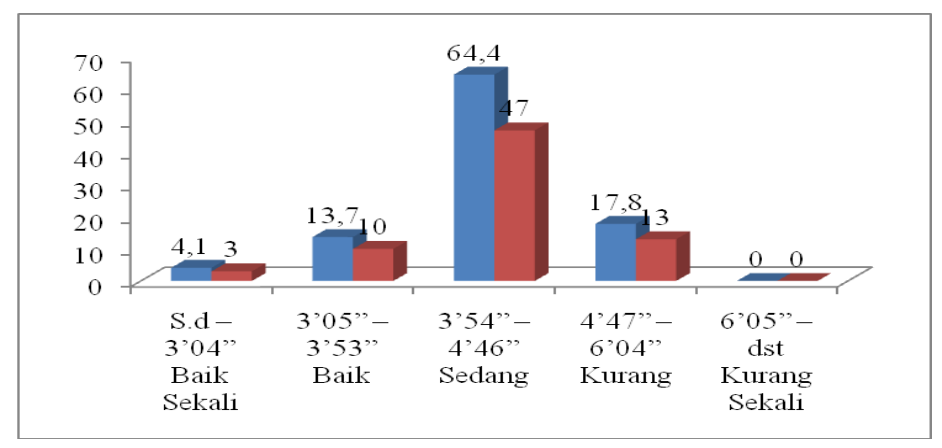

\section{Histogram 5 : Tingkat Lari 600 meter}

Dari histogram data hasil tingkat lari 600 meter di atas dari 73 orang siswa, 3 orang $(4,1 \%)$ tergolong kategori baik sekali, 10 orang $(13,7 \%)$ tergolong kategori baik, 47 orang $(64,4 \%)$ tergolong kategori sedang, 13 orang $(17,8)$ tergolong kategori kurang. Sedangkan untuk yang tergolong kategori kurang sekali tidak ada (0\%). Berdasarkan hasil tes di atas, dapat dikemukakan bahwa rata-rata lari 600 meter adalah 4'08" tergolong kategori sedang.

Tabel. 6 Norma TKJI

\begin{tabular}{|c|c|c|}
\hline No & Jumlah Nilai & $\begin{array}{c}\text { Klasifikasi Kesegaran } \\
\text { Jasmani }\end{array}$ \\
\hline 1. & $22-25$ & Baik Sekali (BS) \\
\hline 2. & $18-21$ & Baik (B) \\
\hline 3. & $14-17$ & Sedang (S) \\
\hline 4. & $10-13$ & Kurang (K) \\
\hline 5. & $5-9$ & Kurang Sekali (KS) \\
\hline
\end{tabular}

Analisis data tentang tingkat kesegaran jasmani secara berurutan di analisis dengan tabel nilai. Agar lebih jelasnya dapat dilihat pada tabel berikut:

Tabel. 7 Nilai TKJI

\begin{tabular}{|c|c|c|c|c|}
\hline No & Tes & Rata-rata & Nilai & Norma \\
\hline 1 & Lari $50 \mathrm{~m}$ & 7.9 & 3 & Sedang \\
\hline 2 & Gantung angkat tubuh & 9 & 3 & Sedang \\
\hline 3 & Baring duduk 30 detik & 24 & 3 & Sedang \\
\hline 4 & Loncat tegak & 47 & 3 & Sedang \\
\hline 5 & Lari $600 \mathrm{~m}$ & 4.08 & 3 & Sedang \\
\hline \multicolumn{3}{|c|}{ Total Rata-rata Nilai TKJI } & 15 & Sedang \\
\hline
\end{tabular}




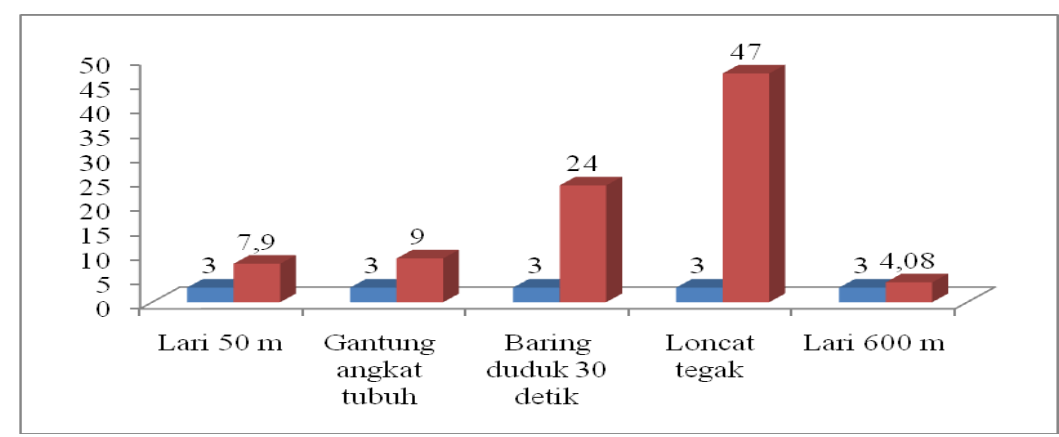

Histogram. 6 Hasil Nilai TKJI

Berdasarkan tabel nilai TKJI di atas, diperoleh rata-rata lari 50 meter $=7.9$ " bernilai 3 tergolong kategori sedang, gantung angkat tubuh $=9$ kali bernilai 3 tergolong kategori sedang, baring duduk 30 detik $=24$ kali bernilai 3 tergolong kategori sedang, loncat tegak $47 \mathrm{~cm}$ bernilai 3 tergolong kategori sedang dan lari 600 meter $=4$ '08' detik bernilai 3 tergolong kategori sedang. Total nilai rata-rata tingkat kesegaran jasmani adalah 15 tergolong kategori sedang.

Dilanjutkan dengan analisis menggunanakan rumus presentase mka hasil penelitian yang didapat adalah terdapat 3 mahasiswa masuk kategori baik sekali sebesar 4,11\%, 9 mahasiswa masuk kategori Baik sebesar 12,33\%, 50 mahasiswa masuk kategori Sedang sebesar 68,49\%, 11 orang mahasiswa masuk kategori kurang sebesar 15,07\%, dan kategori kurang sekali 0\%. Kesimpulan adalah tingkat kesegaran jasmani mahasiswa Program Studi Pendidikan Olahraga semester I Universitas PGRI Palembang rata-rata masuk kedalam kategori Sedang. Sebesar 68,49\%.

\section{Pembahasan}

Berdasarkan analisis data mengenai "Tingkat Kesegaran Jasmani mahasiswa prodi olahraga FKIP Universitas PGRI Palembang”, maka dapat dijawab pertanyaan penelitian yaitu tingkat kesegaran jasmani mahasiswa prodi olahraga FKIP Universitas PGRI Palembang adalah 15 tergolong kategori sedang dengan persentase $68,49 \%$. Artinya, tingkat kesegaran jasmani mahasiswa belum memiliki tingkat kesegaran jasmani yang baik.

Kesegaran jasmani merupakan salah satu aspek penting yang harus dimiliki 
setiap mahasiswa agar bisa mengikuti kegiatan belajar dengan baik. Kesegaran jasmani adalah sesuatu yang sangat bermanfaat untuk mendukung seorang mahasiswa agar berhasil dalam mengikuti kegiatan belajar di sekolah dan merupakan faktor penunjang mahasiswa untuk mampu mencapai hasil belajar yang baik setelah mengikuti usaha belajar.

Kementerian Pendidikan Nasional (2010:1) menyatakan kesegaran jasmani sebagai kemampuan tubuh seseorang untuk melakukan tugas atau pekerjaan sehari-hari tanpa menimbulkan kelelahan yang berarti. Kesegaran jasmani disini adalah suatu kondisi fisik yang prima dimiliki seseorang, sehingga mampu mengerjakan tugas-tugas dan aktivitas sehari-hari tanpa menyebabkan kelelahan yang berarti dalam dirinya.

Mahaiswa yang memiliki kesegaran jasmani yang baik sudah tentu kesehatan yang dimilikinya semakin baik, karena seluruh organ tubuh dapat berfungsi dengan normal. Tetapi, bila mahasiswa itu sehat belum tentu kesegaran jasmani yang dimilikinya baik. Bila kesegaran jasmani mahasiswa menurun, maka akan mempengaruhi terhadap kesehatannya sehubungan daya pikirnya dapat terganggu.

Kesegaran jasmani merupakan suatu hal yang dipengaruhi oleh aktifitas fisik dan latihan olahraga yang dilaksanakan sehari-hari semakin banyak aktifitas dan latihan yang dilakukan mahasiswa, maka semakin baik pula tingkat kesegaran jasmaninya. Hal ini disebabkan dengan aktifitas fisik dan latihan olahraga akan meningkatkan kemampuan tubuh dalam mengkonsumsi oksigen secara maksimal. Apabila tubuh sudah mampu meningkatkan konsumsi oksigen secara maksimal, maka secara otomatis akan berpengaruh terhadap tingkat kesegaran jasmani.

Dengan demikian, dapat dikemukakan bahwa kesegaran jasmani merupakan salah satu faktor penunjang keberhasilan mahasiswa yang dinilai dari hasil belajar. Meskipun pada kenyataan di lapangan ada kalanya mahasiswa yang mempunyai kesegaran jasmani baik, belum tentu diikuti dengan hasil belajar belajar yang baik pula, begitu juga sebaliknya rendahnya hasil belajar belum tentu juga dikarenakan rendahnya tingkat kesegaran jasmani. 


\section{SIMPULAN}

Berdasarkan hasil penelitian yang telah diuraikan dapat dikemukakan kesimpulan bahwa tingkat kesegaran jasmani mahasiswa Prodi Olahraga FKIP Universitas PGRI Palembang adalah 15 tergolong kategori sedang dengan persentase $68,49 \%$. Artinya, belum memiliki tingkat kesegaran jasmani yang baik. Apabila semakin baik tingkat kesegaran jasmani mahasiswa, maka semakin baik tingkat penampilan mahasiswa dalam meningkatkan kualitas belajar. Sebaliknya, apabila tingkat kesegaran jasmani kurang, maka mahasiswa tidak dapat menampilkan kualitas belajar yang baik.

\section{DAFTAR PUSTAKA}

Hairy, Junursul. 2007. Dasar-Dasar Kesehatan Olahraga. Jakarta: Depdiknas Hamalik, Oemar. 2003. Proses Belajar Mengajar. Jakarta: Bumi Aksara.

Kementerian Pendidikan Nasional. 2010. Tes Kesegaran Jasmani Indonesia. Jakarta: Kementerian Pendidikan Nasional Pusat Pengembangan Kualitas Jasmani.

Luthan. 2002. Supervisi Pendidikan Jasmani. Jakarta: Departemen Pendidikan Nasional.

Mutohir, T. Cholik. 2007. Gagasan-Gagasan Tentang Pendidikan Jasmani dan Olahraga. Surabaya: Unesa Universty Press

Riduwan. 2009. Rumus dan Data dalam Analisis Statika. Bandung: Alfebeta.

Sugiyono. 2011. Metode Penelitian Kuantitatif Kualitatif dan $R$ \& D. Bandung: PT Rineka Cipta. 